\title{
Logística Reversa: Uma Análise Comparativa entre Três Processos Reversos de Resíduos Vítreos'
}

\section{Reverse Logistics: A Comparative Analysis of Three Processes Waste Reverse Vitreous}

\author{
Joaquim Carlos Lourenço \\ Mestrando em Recursos Naturais - Programa de Pós-Graduação em Recursos Naturais - UFCG \\ Professor da Universidade Federal Rural de Pernambuco/UAST \\ Universidade Federal Rural de Pernambuco, Unidade Acadêmica de Serra Talhada \\ Fazenda Saco, S/N, Cidade Universitária, CEP: 58109-970 - Serra Talhada, PE - Brasil - Caixa-postal: 063 \\ Telefone: (83) 3310-1199, e-mail: carlosadm2006@gmail.com
}

\author{
Waleska Silveira Lira \\ Professora Doutora da Universidade Estadual da Paraíba e do Programa de Pós-Graduação em Desenvolvimento \\ Regional da Universidade Estadual da Paraíba. \\ Endereço: Universidade Estadual da Paraíba, Departamento de Administração e Economia \\ Rua Getulio Vargas, s/n, Centro, CEP: 58.100-000 - Campina Grande, PB - Brasil \\ Telefone: (83) 3341-3300, e-mail: waleska.silveira@oi.com.br
}

\section{RESUMO}

O presente estudo tem por objetivo fazer uma análise comparativa entre três processos de logística reversa de resíduos vítreos. Para tanto, foi adotado como método, a pesquisa descritiva, e para coleta de dados a pesquisa bibliográfica. $\mathrm{Na}$ análise comparativa dos processos foram utilizados destaques que identificam os itens: Convergência entre os três processos; Divergência entre os três processos; e convergência parcial entre os processos. Assim, para cada item em análise, foi aplicado uma dessas três dimensões para comparar o processo reverso descrito nos estudos. O modelo de análise foi adaptado de Miranda et al. (2003). Os resultados encontrados apontam que os processos logísticos reversos descritos proporcionam vantagens econômicas e ambientais para as empresas. Por outro lado, a implantação dos processos reversos demanda investimentos altos, bem como o mapeamento e padronização dos processos de produção, aspectos estes que supostamente poderão contribuir a continuidade do empreendimento quando adotar esse tipo de prática empresarial.

Palavras-chave: Gestão Ambiental. Reciclagem. Equilíbrio Ecológico.

\begin{abstract}
This study aims to make a comparative analysis between three reverse logistics processes glassy residue. Therefore, it was adopted as a method, descriptive research, data collection and research literature. The comparative analysis highlights the processes were used to identify the items: Convergence between the three processes; divergence between the three cases, and partial convergence between processes. Thus, for each item under examination was applied one of these three dimensions to compare the reverse process described in the studies. The analysis model was adapted from Miranda et al. (2003). The results show that the reverse logistics processes described provide economic and environmental advantages for businesses. Moreover, the implementation of the reverse processes demand high investments, as well as mapping and standardization of production processes, all of which supposedly could help the continuity of the enterprise when adopting this type of business practice.
\end{abstract}

Key-words: Environmental Management. Recycling. Ecological Balance.

\footnotetext{
${ }^{1}$ Artigo recebido em 10.09.2012. Revisado por pares em 20.11.2012 (blind review). Reformulado em 05.12.2012. Recomendado para publicação em 21.12.2012 por José Ribamar Marques de Carvalho (Editor Científico). Publicado em 28.12.2012.
}

REUNIR - Revista de Administração, Contabilidade e Sustentabilidade - Vol. 2, no 4, p.19-34, Set-Dez/2012.

ISSN: $2237-3667$ 


\section{INTRODUÇÃO}

A Revolução Industrial do século passado, associada às inovações tecnológicas, possibilitou a ascensão da produção em massa. Esse modo de produção idealizado por Henry Ford nos Estados Unidos permitiu a redução nos custos do trabalho com o aumento nas taxas de produção, e, por conseguinte, possibilitou a produção de produtos por um preço mais baixo. Sob essa perspectiva, e com o impulso do desenvolvimento industrial, os mercados foram inundados por uma oferta constante e diversificada de novos produtos.

Como reflexo de tal cenário, a produção de bens industrializados cresceu muito, resultando em maior uso dos recursos naturais, sobretudo, após a Segunda Guerra Mundial (1939-1945), quando a economia mundial entrou numa era de forte competitividade entre os mercados. Nesse cenário, alguns países influenciados por razões econômicas abandonaram seus programas de conservação dos recursos naturais estabelecidos durante a guerra, mas foram continuados em alguns países sem uma abundância de recursos naturais, como o Japão.

O desenvolvimento tecnológico e as constantes inovações aceleraram a obsolescência dos produtos, principalmente por reduz seus ciclos de vida, deixando clara a tendência de descartabilidade dos produtos (RESENDE, 2004). Não obstante, a utilização excessiva dos recursos naturais como matéria-prima nos processos produtivos tem provocado graves problemas socioambientais ao longo dos últimos anos em todo planeta, como o aquecimento global que tem provocado inundações, secas, falta de alimentos devido à queda da produção em algumas regiões e de água potável nas regiões mais áridas do planeta.

A preocupação com essa situação fez com que surgisse a mobilização da sociedade, exigindo soluções e mudanças nos sistemas e modos de produção, objetivando a preservação da natureza e a redução de poluentes. Nessa perspectiva, nos últimos anos aumentou a consciência ecológica e muitos consumidores se tornaram mais exigentes, demandando assim produtos menos agressivos ao meio ambiente. Nesse sentido, a indústria também tem mostrado um maior interesse pelas questões ambientais devido ao aumento da poluição, diminuição das fontes de recursos não renováveis, desenvolvimento de legislações preventivas e crescimento da demanda de produtos e processos de produção "verde".

Diante de tal realidade, e para atender essa tendência bioeconômica, as empresas têm buscado aderir aos princípios da responsabilidade socioambiental. Algumas em busca de melhorias na própria imagem perante aos consumidores, outras buscando redução de custos, aumento de receitas e diferencial competitivo. Nesse contexto, surge à logística reversa que trata do retorno dos subprodutos não utilizados, por meio de canais de distribuição de fluxo inverso dos resíduos gerados nos processos produtivos, prestação de serviços e bens pósconsumo.

Independentemente do tipo de resíduo gerado, a logística reversa tem as ferramentas apropriadas para dá uma destinação adequada, seja por meio da reciclagem, reuso e/ou desmanche. No caso específico da cadeia produtiva do vidro, o acúmulo de resíduos tem forçado as indústrias desse setor a buscar novas possibilidades de uso para esses materiais, uma vez que o vidro é totalmente reciclável e o seu tempo de permanência no meio ambiente sem se degradar pode ser determinado.

Atualmente, o Brasil recicla apenas $47 \%$ das embalagens e resíduos de vidro, segundo a Abividro - Associação Brasileira da Indústria do Vidro, (2008). Não obstante, nos próximos anos, esse quadro tende a mudar em função principalmente da Política Nacional de Resíduos Sólidos, que traz para os vendedores e fabricantes parte da responsabilidade no descarte dos 
resíduos dos produtos e embalagens. Logo, eles serão obrigados a estruturar e implementar sistemas de logística reversa em todos os segmentos, inclusive no de vidros que se encaixa perfeitamente em um programa de logística reversa.

Frente a esse cenário, o estudo busca responder o seguinte questionamento: Como os processos reversos descritos na literatura podem auxiliar as organizações na implementação de seus canais reversos? Em outras palavras, uma análise comparativa entre processos de logística reversa, em especial a de resíduos vítreos descrita na literatura, pode demonstrar a importância da logística reversa para as organizações e ajudar na confecção de um processo reverso adequado para os resíduos vítreos?

Desse modo, partindo do problema, o presente estudo tem por objetivo fazer uma análise comparativa entre três processos de logística reversa de resíduos vítreos. Para tanto, foi selecionado três estudos de logística reversa de resíduos vítreos publicados em periódicos científicos, sendo eles: análise da gestão de logística reversa de vasilhames de vidro em uma fábrica de refrigerantes (MARÇAL; SILVA, 2008); gestão de resíduos sólidos: um estudo sobre as vantagens ambientais e econômicas da logística reversa em uma empresa de fabricação de vidros (OLIVEIRA NETO et al., 2011); e logística reversa numa empresa de laminação de vidros: um estudo de caso (GONÇALVES; MARINS, 2006).

Os estudos foram selecionados pelo critério de intencionalidade. Além deste critério, na escolha dos estudos foram priorizados os seguintes requisitos: à relevância do estudo e o seu direcionamento para o tema. Com base nestes critérios, foram selecionados os três estudos/artigos de logística reversa de resíduos vítreos mais relevantes dos periódicos nacionais, conforme percepção do pesquisador. $\mathrm{O}$ trabalho procurará apontar as semelhanças e divergências relevantes entre esses três processos reversos descritos nos estudos.

Este trabalho se justifica uma vez que a geração de resíduos aumenta cada vez mais, e, por conseguinte, os locais para o descarte diminuem. Logo, a logística reversa surge como uma alternativa para o gerenciamento ecologicamente correto dos resíduos. E também pela relevância que o tema vem recebendo a cada dia, bem como pela ausência de estudos sistemáticos que trate da logística reversa do vidro, que tem um ciclo de decomposição indeterminado na natureza.

\section{REFERENCIAL TEÓRICO}

\subsection{Logística Reversa}

A logística reversa na prática existe e vem sendo usada desde que se iniciou o comércio de mercadorias. Ou seja, a troca de mercadorias com defeitos ou danificadas era comum no comércio desde os tempos antigos, e esta prática concretiza um tipo de fluxo reverso. Apesar disso, foi somente no século XX, na década de 90 que o conceito de logística reversa evoluiu impulsionado pelo aumento da preocupação com questões de preservação do meio ambiente. A partir deste período, as empresas de processamento e distribuição passaram a ver a logística reversa com outros olhos, sobretudo, devido ao aumento da pressão induzida pelos consumidores, que posteriormente implicou em ações legais dos órgãos fiscalizadores.

Inicialmente, as atividades de logística reversa passaram a ser utilizadas com maior intensidade nos Estados Unidos e Europa, países onde os conceitos e ferramentas clássicas de logística já eram mais disseminados (BARRATT, 2004; FLEYRY, 1999; FERREIRA et al., 2010). Enquanto isso no Brasil, embora seja notável o potencial da logística reversa na 
economia, a falta de visão da atividade como potencial gerador de vantagem competitiva às empresas compromete a estruturação dos canais e funcionamento de forma eficiente, mesmo nos canais mais tradicionais e melhor estruturados.

Atualmente, com a redução do tempo de ciclo dos produtos, o foco de atuação da logística reversa envolve a reintrodução dos produtos ou materiais à cadeia de valor por sua reinserção no ciclo de produção ou de negócios e, portanto, um produto só é descartado em último caso. Isto porque o processo logístico reverso pode prolongar o reuso dos produtos descartados e/ou seus componentes, principalmente, reintroduzindo-os nos processos produtivos em forma de matéria-prima ou novos produtos remanufaturados.

O processo de logística abrange desde a etapa inicial, partindo-se da matéria-prima até a entrega do produto ao consumidor. No entanto, conforme Santos (2010), é possível estender os estudos além deste ponto e analisar o fluxo inverso ao da cadeia tradicional, ou seja, o produto partindo-se do consumidor final até sua reutilização, evitando assim o descarte incorreto no meio ambiente. Ainda de acordo com o mesmo autor, o estudo desse fluxo inverso da logística é denominado logística reversa.

A logística reversa pode ser entendida como a área da logística que planeja, opera e controla o fluxo de matérias-primas, da produção e do produto acabado (e seu fluxo de informação), do ponto de consumo até a origem, com o fim de recapturar valor ou oferecer um destino ecologicamente adequado, por meio dos canais de distribuição reversos, agregandolhes valor de diversas naturezas: econômico, ecológico, legal, logístico, de imagem corporativa, entre outros.

Para Daher et al. (2004), a logística reversa em seu sentido mais amplo, significa todas as operações relacionadas com a reutilização de produtos e materiais. Refere-se, assim, a todas as atividades logísticas de coletar, desmontar e processar produtos e/ou materiais e peças usadas a fim de assegurar uma recuperação sustentável antes do descarte dos componentes inutilizáveis no meio ambiente.

Nessa perspectiva, a logística reversa torna-se uma das mais importantes áreas dentro da empresa, sobretudo, nas empresas modernas, face ao crescente ambiente de competitividade e de sensibilidade ecológica da sociedade. Contudo, o sucesso do canal reverso depende do tipo de material e o motivo pelo qual ele entrou no sistema. Os produtos, em geral, retornam devido a uma necessidade de reparo, reciclagem, descarte ou simplesmente porque os clientes os devolveram por não gostar.

Pela ótica de Novaes (2007), a logística reversa cuida dos fluxos de materiais que se iniciam nos pontos de consumo dos produtos e terminam nos pontos de origem, com o objetivo de recapturar valor ou de disposição final. Ou seja, o processo de logística reversa envolve a movimentação de produtos através de canais reversos de distribuição, com o propósito de atender os requisitos dos clientes e/ou para o retorno ao ciclo de negócios, ou para disposição final adequada em aterros sanitários, depois de esgotada todas as possibilidades de reuso.

A logística reversa atua em duas grandes áreas, a logística reversa de pós-venda e de pós-consumo, sendo estas diferenciadas pelo estágio ou fase do ciclo de vida útil do produto retornado. A logística pós-venda se ocupa do equacionamento e operacionalização do fluxo físico e das informações logísticas correspondentes de bens pós-venda, sem uso ou com pouco uso, que por diferentes motivos retornam aos diferentes elos da cadeia de distribuição direta.

Segundo Leite (2003), o canal de distribuição reverso pós-venda é caracterizado pelo retorno de produto que apresentaram problemas. Por isso, o objetivo estratégico dessa área da 
logística é agregar valor ao produto logístico que é devolvido por razões comerciais, erros no processamento dos pedidos, garantia dada pelo fabricante, defeitos ou falhas de funcionamento, avarias no transporte, manuseio, entre outros. Assim, esse fluxo de retorno se estabelecerá entre os diversos elos da cadeia de distribuição direta, dependendo do objetivo estratégico ou do motivo de retorno.

Já a logística reversa de pós-consumo é responsável pelo retorno dos produtos descartados pela sociedade em geral. Através desse canal os bens pós-consumo retornam ao ciclo de negócios ou ao ciclo produtivo por meio dos canais de distribuição reversos específicos. Os produtos coletados nesse canal podem ser divididos em duas categorias: produtos ainda em condições de uso e que podem ser recolocados no mercado como produtos de segunda mão, e aqueles em fim de vida útil, que poderão ter seus componentes reutilizados em outros produtos, ser reciclados ou descartados por não ter mais condição de uso.

Para Leite (2005), os materiais descartados nesse canal podem ser enviados a destinos finais tradicionais, como a incineração ou os aterros sanitários, considerados meios seguros de estocagem e eliminação, ou retornar ao ciclo produtivo por meio de canais de desmanche, reciclagem ou reuso em uma extensão de sua vida útil.

Segundo Guarnieri (2005), essa vida útil pode ser prolongada se outras pessoas virem neste mesmo bem, outras utilidades o mantendo em uso por um determinado tempo, após isso esse bem é destinado à coleta de lixo urbano, podendo ser reciclado ou simplesmente depositado em aterros sanitários, causando sérios impactos ao meio ambiente.

Corroborando com essa visão, Leite (2003) destaca que a disposição final segura dos bens pós-consumo usando-se um meio controlado que não danifique, de alguma maneira o meio ambiente e que não atinja, direta ou indiretamente a sociedade é essencial. Deste modo, as alternativas de retorno de produtos ao ciclo produtivo constituem-se atualmente na principal preocupação do estudo da logística reversa e dos canais de distribuição reversos de pós-venda e pós-consumo.

Este trabalho será focado nos aspectos da logística reversa de pós-consumo, processo reverso que tem como alternativa a reciclagem, o reuso e o desmanche, sendo este último realizado após esgotada todas as possibilidades de uso, buscando assim aproveitar componentes, e, por conseguinte, inserir-lhes novamente na cadeia produtiva em forma de matéria-prima e/ou novos produtos. É deste contexto que surge a logística reversa dos resíduos vítreos, que será analisada nesse trabalho.

\section{PROCEDIMENTOS METODOLÓGICOS}

O presente trabalho constitui-se quanto aos objetivos em uma pesquisa descritiva (GIL, 2007; VERGARA, 2007), com abordagem qualitativa. Também constitui-se em um estudo comparativo entre três processos de logística reversa de resíduos vítreos. Quanto aos procedimentos adotados na coleta de dados foi utilizada a pesquisa bibliográfica (GIL, 2007), que se fundamenta a partir do conhecimento disponível em fontes bibliográficas, principalmente em livros, monografias, dissertações, teses e artigos científicos.

Em virtude de limitações no decorrer do trabalho, sobretudo, para localizar um número considerável de estudos de logística reversa aplicados aos resíduos vítreos, optou-se por selecionar estudos de logística reversa sobre o vidro por meio de uma amostra não probabilística, selecionada pelo critério de intencionalidade (GIL, 2007; VERGARA, 2007). 
Além deste critério, na escolha dos estudos foram priorizados os seguintes requisitos: à relevância do estudo e o seu direcionamento para o tema.

Sob essa perspectiva, os estudos (artigos científicos) selecionados para a análise comparativa foram os seguintes: Marçal e Silva (2008) - Análise da gestão de logística reversa de vasilhames de vidro em uma fábrica de refrigerantes (4.1.1 Estudo I); Oliveira Neto et al. (2011) - Gestão de resíduos sólidos: um estudo sobre as vantagens ambientais e econômicas da logística reversa em uma empresa de fabricação de vidros (4.1.2 Estudo II); Gonçalves e Marins (2006) - Logística reversa numa empresa de laminação de vidros: um estudo de caso (4.1.3 Estudo III).

Neste trabalho, para simplificação de nomenclatura, o termo "processos" será algumas vezes utilizado, para nomear os processos reversos e/ou os estudos analisados. Além disto, para um melhor entendimento dos três estudos/artigos aqui analisados, os mesmos serão denominados nesse trabalho de estudo: "I", "II" e "III". Esta opção tornou-se necessária e justifica-se, pela maior facilidade na descrição e representação gráfica dos estudos analisados, uma vez que estes possuem títulos extensos.

Para realizar a análise comparativa, buscou-se identificar as relações comuns entre os estudos, com o intuito de criar as condições adequadas para a comparação. O modelo foi adaptado de Miranda et al. (2003). Para a comparação foi utilizado cores que identificavam os itens como sendo: Convergência entre os três processos; Divergência entre os três processos; e Convergência parcial entre os processos. Os itens comparados foram: Fluxo reverso adotado; Gestão do processo; Processo reverso; Infraestrutura do processo reverso; Tipo do segmento; Atores externos envolvidos no processo reverso; Eficiência do processo reverso; Investimento demandado; Mudanças necessárias para instalar o processo reverso; Enfoque do processo reverso; e vantagens proporcionada pela implementação do processo reverso.

Segundo Santos (2009) é comum nas análises em ciências sociais aplicadas, a exemplo da administração e economia, dar nomes a cada agrupamento de acordo com suas características. Para o autor, é comum realizar também uma análise descritiva comparativa para a validação dos agrupamentos, tomando, como referência, variáveis selecionadas. Neste trabalho, a análise buscou apontar as semelhanças e as diferenças entre os três processos de logística reversa, bem como promover uma reflexão para uma proposta de um modelo de gestão integrada dos resíduos de vidro, de acordo com as disposições da Política Nacional de Resíduos Sólidos. Por fim, a análise qualitativa final dos dados foi feita através dos métodos interpretativo e comparativo (RAUEN, 1999).

\section{APRESENTAÇÃO E DISCUSSÃO DOS RESULTADOS}

Esta seção foi dividida em duas partes. Na primeira parte são apresentados de forma sucinta os processos de logística reversa de resíduos vítreos descritos em três estudos (artigos científicos) selecionados pelo pesquisador. Na segunda parte é feita uma análise comparativa entre os três processos reversos delineados nos estudos escolhidos. Os resultados obtidos são baseados nos três estudos, especificamente na análise comparativa entre eles. 


\subsection{Apresentação dos estudos}

\subsubsection{Estudo I}

O estudo "I" trata-se de uma análise realizada por Marçal e Silva (2008) da gestão de logística reversa de vasilhames de vidro em uma fábrica de refrigerantes, especificamente, a Companhia Paraense de Refrigerantes, COMPAR, cuja é responsável pela fabricação e distribuição de refrigerantes. Está localizada na região metropolitana de Belém, no estado do Pará e foi estabelecida na cidade no ano de 1990. Sua malha logística consiste em uma fábrica e cinco centros de distribuição. A empresa produz um mix de vários sabores e tamanhos de refrigerantes, envasados em garrafas tipo pet e em garrafas de vidro retornáveis também denominadas vasilhames operacionais.

O processo de logística reversa das garrafas de vidro retornáveis instalado na Companhia compreende a coleta, classificação, controle e reciclagem. O processo reverso inicia-se logo após o consumo da bebida pelo cliente, do qual é recolhido o vasilhame pelo setor de logística e distribuição; esta, ao chegar à fábrica, leva-os ao estoque, mas apenas depois de conferidos para verificar se há garrafas quebradas, bicadas ou estouradas. Essa inspeção corrobora para que os vasilhames sejam reinseridos no processo produtivo e/ou para reciclagem, caso seja detectado algum problema.

O setor de produção ao verificar a necessidade de envase de determinado produto solicita a quantidade de vasilhames necessários ao setor de estoque que os envia para serem envasados, retornando assim à condição de produtos acabados. São então enviados ao estoque, que os libera para a distribuição, com suas respectivas notas fiscais e rotas de entrega predeterminadas ao cliente, reiniciando o fluxo reverso. $\mathrm{O}$ fluxo reverso dos vasilhames de vidro contribui para a redução dos custos controláveis de produção, pois proporciona a reutilização dos vasilhames de vidros na produção reintegrando-os à cadeia logística, gerando assim economia.

Além disso, Marçal e Silva (2008) constataram que o reuso das embalagens de vidro pela Companhia agrega valor ao produto; melhora a imagem coorporativa da empresa quanto ao respeito ao meio ambiente e traz uma margem de contribuição muito maior que o produto envasado em garrafas pet para o resultado operacional da empresa. Devido a estas vantagens específicas, a empresa possui uma estação de tratamento de efluentes, cuja além de receber e dar destinado adequado a todos os resíduos sólidos, inclusive o vidro das garrafas danificadas e inservíveis, trata toda água utilizada na empresa, devolvendo-a limpa ao meio ambiente.

Note-se que a principal razão para a adoção e continuidade deste processo de gestão, é a economia de escala proporcionada pelo reuso e reciclagem dos vasilhames de vidro e a otimização do processo pela reutilização da embalagem do produto. Por isso, a logística de retorno desses vasilhames assume um papel estratégico singular para a empresa. Outro ponto relevante a se destacar é o processo reverso implantado na empresa, é todo automatizado, ou seja, o fluxo reverso tem todas suas etapas padronizadas.

Além disto, a gestão é compartilhada com os atores externos. Todavia, para se implementar o processo reverso, é preciso fazer a instalação de um sistema de informação para a gestão do estoque e integrar o canal reverso com a produção. E, essas mudanças demandam investimentos altos. Por último, a logística reversa realizada pela empresa prolonga pelo reuso dos vasilhames de vidro o ciclo de vida destes. 


\subsubsection{Estudo II}

O estudo "II" refere-se a um estudo sobre as vantagens ambientais e econômicas da logística reversa em uma empresa de fabricação de vidros, ou seja, mostra a gestão de resíduos sólidos em uma empresa multinacional fornecedora de vidros para o mercado nacional e internacional. Esse processo de logística reversa do vidro delineado por Oliveira Neto et al. (2011), considera todos os resíduos de vidros que foram avariados nos processos de logística interna e externamente a organização. Assim, os resíduos de vidros gerados no processo de carga, descarga do transporte e no momento de fixação nos prédios é reciclado.

O fluxo reverso apresenta um processo simples, inicialmente, um departamento que classifica e recicla os resíduos de vidros recebe todos os materiais entregues pelos fornecedores, inclusive os resíduos de vidros depois de britados (quebrados em pequenos fragmentos), em seguida o material é classificado para verificar se houver avarias nos departamentos internos, na sequência, encaminha-se para inspeção e análise dos componentes recebidos antes de processar a fim de avaliar as características físicas do material. Nesse caso, se o material estiver dentro dos padrões estipulados, segue para a usina de composição para ser transformado em um novo produto.

Essa inspeção é necessária para que os resíduos possam ser reaproveitados, como também é necessário que eles estejam nas condições adequadas e exigidas para a sua entrada em um novo processo de produção, pois não se trata apenas da produção de produtos, mas sim, a preocupação com seu destino final. Vislumbrando tudo isso, o processo logístico instalado tem o fluxo reverso dos resíduos de vidros todo automatizado e todas as etapas do processo padronizadas. As etapas de coleta do material para reuso e reciclagem são as seguintes: Recebimento; Classificação e Reciclagem de Resíduos de Vidros; Inspeção e análise dos componentes recebidos; Usina de composição; Misturador; Forno; e laminação.

Os resíduos produzidos pelos clientes são coletados por um Operador Logístico contratado pela empresa. A infraestrutura do processo reverso funciona integrada ao processo produtivo e sua gestão é compartilhada com os atores externos, fornecedores, operadores terceirizados e clientes finais. O processo reverso permite que a empresa atinja seus objetivos com menos recursos, uma vez que este proporciona vantagens econômicas e ambientais com a redução da compra de embalagens e com a redução dos impactos ambientais, por meio do reuso de $100 \%$ dos resíduos vítreos gerados.

No entanto, a implantação do canal reverso demanda investimentos muito altos, sobretudo, para a instalação de um departamento para gerenciar todo o processo, usina de composição e compra de equipamentos (máquina britadora, misturador e forno). Não obstante, o processo de Logística Reversa de resíduos de vidros proporciona aumento da receita líquida da empresa. Nesse caso é possível ter melhores resultados financeiros quando se reusa matéria-prima e pratica a Logística Reversa no cerne do gerenciamento da cadeia de suprimentos.

\subsubsection{Estudo III}

O estudo "III" foi desenvolvido numa empresa de laminação de vidros localizada no Estado de São Paulo. A empresa é responsável pela produção do PVB (Polivinilbutiral). O PVB é utilizado como uma película de proteção intercalada nos vidros de automóveis, carros 
e aviões. A empresa trabalha com uma gama diversificada de produtos, a partir de várias formulações, que objetivam o atendimento das especificações fixadas pelos clientes.

O processo de logística reversa descrito por Gonçalves e Marins (2006), compartilha a gestão dos resíduos com os clientes. Os clientes da organização realizam a laminação dos vidros a partir do produto acabado. No final, sobram as rebarbas deste processo, as quais são denominadas aparas. As aparas não possuem valor agregado para o beneficiador do vidro laminado, mas podem ser reinseridas no processo de produção do PVB.

Antes da implantação do processo verso, essas aparas usualmente eram descartadas pelos beneficiadores de vidro, no entanto aspectos relativos ao impacto ecológico e financeiro ganharam relevância. Por isso, o modelo foi desenvolvido. Tal modelo tem como intuito fazer a reutilização das aparas geradas pelos clientes da organização no processo produtivo.

No entanto, para implantar o processo, inicialmente, deve-se fazer um mapeamento dos principais (macros) processos da empresa para posteriormente definir as atividades do processo logístico reverso. O mapeamento é necessário para cintilar um melhor entendimento do processo produtivo, e, por conseguinte, dos gargalos existentes em cada etapa da cadeia de suprimentos.

Nesse sentido, para Gonçalves e Marins (2006), o modelo SCOR - Supply Chain Operations Reference -, que é um modelo de referência para o gerenciamento de Cadeias de Suprimentos pode ajudar as empresas na avaliação do desempenho da sua própria cadeia, identificando áreas fracas e desenvolvendo soluções de melhoria. Essa análise pode minimizar as dificuldades que aparecem na implementação do processo de reuso de aparas em virtude das alterações necessárias no sistema de planejamento e controle produtivo.

Depois de instalado o processo verso controla a entrada e saída dos resíduos baseado na quantidade de produto enviada para o cliente, também se calcula a quantidade e data de retorno do material de reuso. O controle de entrada é realizado para impedir que materiais estranhos integrem o fluxo logístico reverso. Sabe-se que sistemas de logística reversa que possuem controles de entrada defasados geram sérias dificuldades posteriores, e isto se reflete na efetivação do processo. Nesse sentido, a implementação de um sistema de código de barras e lotes facilitou o set ups e o controle de propriedades físicas e químicas.

Nessas condições, o processo verso tem como objetivo proporcionar um retorno otimizado das aparas dos clientes e fornecedores. Por isso foram firmadas parcerias do tipo ganha-ganha, antes dessa iniciativa, os clientes eram os responsáveis pela disposição final das aparas, ou seja, os custos eram somente deles e, além disso, não havia a possibilidade dos descontos na compra de novos produtos, isso foi introduzido após a adoção da logística reversa. Vislumbrando tal oportunidade, os clientes compradores de grandes quantidades de produto recebem descontos no valor de compra do produto acabado, descontos de pequenas taxas, facilidades de pagamento e entrega do produto na porta.

Sob essa perspectiva, foi implementado um sistema Kanban e alterado o plano mestre de produção. Além disso, foi necessária a introdução de um novo plano de reprocesso para as aparas. Nesse aspecto, a infraestrutura montada é integrada com o processo produtivo e todas as etapas do fluxo reverso são padronizadas. Muito embora a implementação de um processo logístico reverso seja considerado caro, haja vista requer uma infraestrutura logística adequada.

Por fim, as mudanças necessárias para instalar o processo reverso requer um investimento muito alto. Por outro lado, pode levar a uma redução de custo na cadeia produtiva, ganho de know-how sobre o sistema logístico completo, redução do consumo de 
matéria-prima virgem, do custo do produto acabado e redução dos impactos ambientais, além de reciclar todos os resíduos de vidro e de outros materiais gerados.

\subsection{Análise comparativa entre os três processos reversos}

Nessa seção, procede-se à análise comparativa dos três processos reversos descritos nos estudos: "I", "II" e "III". Com base na pesquisa bibliográfica realizada, criou-se uma estrutura de análise ausente em medidas estatísticas. O modelo foi adaptado de Miranda et al.(2003). Ademais para realizar a análise comparativa das variáveis presentes nos processos reversos delineados nos estudos, utilizou-se cores que identificam os itens como sendo: Convergência entre os três processos; Divergência entre os três processos; e convergência parcial entre os processos.

Assim, para cada item em análise, foi aplicado uma dessas três dimensões para comparar os processos reversos/estudos em análise. Os itens selecionados estão presentes parcialmente nos três processos reversos/estudos, porque para realizar a análise comparativa proposta é preciso que haja uma homogeneidade entre os processos, e como cada processo tem especificidades próprias que dificultam ou impossibilitam uma comparação linear e direta entre eles, optou-se por essa seleção. No entanto, houve a preocupação em selecionar apenas os itens considerados relevantes para a análise e presente simultaneamente nos estudos, mesmo que implicitamente (Quadro 1).

\begin{tabular}{|c|c|c|c|c|}
\hline $\begin{array}{c}\text { Item } \\
\text { Comparado }\end{array}$ & Estudo I & Estudo II & Estudo III & Comparação \\
\hline $\begin{array}{l}\text { Fluxo reverso } \\
\text { adotado }\end{array}$ & Padronizado & Padronizado & Padronizado & \\
\hline $\begin{array}{l}\text { Gestão do } \\
\text { processo }\end{array}$ & Compartilhada & Compartilhada & Compartilhada & \\
\hline $\begin{array}{l}\text { Processo } \\
\text { reverso }\end{array}$ & Automatizado & Automatizado & Automatizado & \\
\hline $\begin{array}{l}\text { Infraestrutura } \\
\text { do processo } \\
\text { reverso }\end{array}$ & $\begin{array}{lll}\begin{array}{l}\text { Integrada } \\
\text { produção }\end{array} & \text { com } \quad \text { a }\end{array}$ & $\begin{array}{l}\text { Integrada ao processo } \\
\text { produtivo }\end{array}$ & $\begin{array}{l}\text { Integrada ao processo } \\
\text { produtivo }\end{array}$ & \\
\hline $\begin{array}{l}\text { Tipo do } \\
\text { segmento }\end{array}$ & Produção e distribuição & Distribuição & Produção & \\
\hline $\begin{array}{l}\text { Atores externos } \\
\text { envolvidos no } \\
\text { processo } \\
\text { reverso } \\
\end{array}$ & Clientes & $\begin{array}{l}\text { Fornecedores, } \\
\text { operadores } \\
\text { terceirizados e clientes }\end{array}$ & $\begin{array}{ll}\text { Clientes } & \mathrm{e} \\
\text { Fornecedores } & \end{array}$ & \\
\hline $\begin{array}{l}\text { Eficiência do } \\
\text { processo } \\
\text { reverso } \\
\end{array}$ & $\begin{array}{l}\text { Dar destino adequado } \\
\text { aos resíduos de vidro e } \\
\text { a todos outros gerados }\end{array}$ & $\begin{array}{l}\text { O resíduo de vidro } \\
\text { gerado é reusado } 100 \%\end{array}$ & $\begin{array}{l}\text { Recicla os resíduos de } \\
\text { vidro e de outros } \\
\text { materiais }\end{array}$ & \\
\hline $\begin{array}{l}\text { Investimento } \\
\text { demandado }\end{array}$ & Alto & Muito alto & Muito alto & \\
\hline $\begin{array}{l}\text { Mudanças } \\
\text { necessárias } \\
\text { para instalar o } \\
\text { processo } \\
\text { reverso } \\
\end{array}$ & $\begin{array}{lcr}\text { Instalação } & \text { de } & \text { um } \\
\text { sistema de informação } \\
\text { para a gestão do } \\
\text { estoque }\end{array}$ & $\begin{array}{l}\text { Implantação de um } \\
\text { departamento } \\
\text { gerencial o processo e } \\
\text { uma usina }\end{array}$ & $\begin{array}{lr}\text { Mapeamento } & \mathrm{e} \\
\text { entendimento } & \text { dos } \\
\text { processos atuais } & \end{array}$ & \\
\hline $\begin{array}{l}\text { Enfoque do } \\
\text { processo }\end{array}$ & $\begin{array}{lr}\text { Estratégico } & \text { (influencia } \\
\text { no } & \text { resultado } \\
\end{array}$ & $\begin{array}{l}\text { Estratégico } \text { (aumento } \\
\text { da receita líquida da }\end{array}$ & $\begin{array}{l}\text { Estratégico } \text { (redução } \\
\text { do consumo de }\end{array}$ & \\
\hline
\end{tabular}

REUNIR - Revista de Administração, Contabilidade e Sustentabilidade - Vol. 2, nº 4, p.19-34, Set-Dez/2012.

ISSN: 2237-3667 


\begin{tabular}{|c|c|c|c|}
\hline reverso & $\begin{array}{l}\text { operacional da } \\
\text { empresa) e operacional } \\
\text { (execução e controle } \\
\text { das atividades) }\end{array}$ & $\begin{array}{l}\text { empresa,) } \\
\text { operacional } \\
\text { (terceirização das } \\
\text { atividades de coleta) }\end{array}$ & $\begin{array}{l}\text { matéria-prima virgem e } \\
\text { do custo do produto } \\
\text { acabado) e operacional } \\
\text { (execução e controle } \\
\text { das atividades) }\end{array}$ \\
\hline $\begin{array}{l}\text { Vantagens } \\
\text { proporcionada } \\
\text { pela } \\
\text { implementação } \\
\text { do processo } \\
\text { reverso }\end{array}$ & $\begin{array}{lr}\text { Redução dos } & \text { custos } \\
\text { controláveis } & \text { de } \\
\text { produção; otimização } \\
\text { do processo } \\
\text { revalorização } \\
\text { ecológica. }\end{array}$ & $\begin{array}{l}\text { Econômica com } \\
\text { redução da compra de } \\
\text { embalagens } \\
\text { ambiental com a } \\
\text { redução dos impactos }\end{array}$ & $\begin{array}{l}\begin{array}{l}\text { Redução de } \\
\text { cadeia }\end{array} \text { produto na } \\
\text { ganho de know-how } \\
\text { sobre o sistema } \\
\text { logístico completo e } \\
\text { redução dos impactos } \\
\text { ambientais }\end{array}$ \\
\hline \multicolumn{4}{|c|}{$\begin{array}{l}\text { Legenda: } \\
\text { Convergência entre os três processos } \\
\text { Divergência entre os três processos } \\
\text { Convergência parcial entre os processos }\end{array}$} \\
\hline
\end{tabular}

Quadro 1 - Resumo das comparações entre os processos reversos "I", "II" e "III" Fonte: Adaptado de Miranda et al. (2003).

Os três estudos em análise descrevem um fluxo reverso padronizado, ou seja, todos os processos necessários para a reutilização/reciclagem dos resíduos de vidro são controlados. $\mathrm{O}$ fluxo reverso dos vasilhames no estudo "I" inicia logo após o consumo da bebida pelo cliente, do qual é recolhido o vasilhame pelo setor de logística e distribuição; Enquanto que no estudo "II" o fluxo começa logo após a coleta e/ou entrega dos resíduos de vidro pelos fornecedores/operador logístico; já no estudo "III" o processo de reuso de aparas de vidro tem início depois da coleta e/ou devoluções dos resíduos pelos clientes.

Segundo Souza (2008) os clássicos canais logísticos reversos são comuns em muitas empresas. Por exemplo, fabricantes de bebidas gerenciam todo o retorno das garrafas dos pontos de venda até seus centros de distribuição. A estes sinais, deve-se acrescentar o fato do crescimento do segmento de embalagens, itens altamente descartável, que tem se adaptado e contribuído significativamente, para as modificações mercadológicas e logísticas requeridas na distribuição física.

Note-se que no processo descrito no estudo "III" os clientes recebem vantagens econômicas para participarem de forma proativa do fluxo reverso, são parcerias do tipo ganha-ganha, onde os clientes compradores de grandes quantidades de produto recebem descontos no valor de compra do produto acabado, descontos de pequenas taxas, facilidades de pagamento e sistemas de entrega do tipo porta a porta. Em relação à gestão do fluxo reverso, em todos os estudos foi constatado que o processo funciona de forma compartilhada parcialmente com atores externos, como, fornecedores, operadores logísticos e clientes. No estudo "II" a coleta e reciclagem dos resíduos de vidro é feita por um operador logístico terceirizado.

O processo de logística reversa dos estudos em análise são todos automatizados, e, por isso, seus procedimentos de reciclagem têm que obedecer a uma sequência de atividades, que são as seguintes: coleta do material, classificação, análise do estado dos componentes recebidos antes de processar a fim de avaliar as características físicas do material, principalmente para saber se há impurezas no meio dos cacos de vidro, e por último o material 
é reprocessado para retornar ao sistema logístico, em forma de matéria-prima ou produto acabado.

Nesse sentido, o processo logístico reverso requer uma infraestrutura logística adequada para lidar com os fluxos de entrada dos materiais reutilizados. Assim como instalações de armazenagem e sistemas de controle devem ser desenvolvidos para interligar de forma eficiente os pontos de coleta (clientes) até o ponto de consumo (empresa), ou seja, o processo logístico reverso deve funcionar integrado ao processo produtivo. Nesse caso é indispensável salientar que, os três processos apresentam essa configuração, apesar do investimento demandado para sua implementação ser considerado muito alto para dois dos processos (Quadro 1).

Por outro lado, percebeu-se que o processo logístico reverso proporciona vantagens para os três processos, para o processo "I", por exemplo, causa elevado apelo junto ao público consumidor dos produtos retornáveis, redução dos custos controláveis de produção, otimização do processo produtivo e revalorização ecológica, pois impede que sejam depositados no meio ambiente os vasilhames de refrigerantes após seu uso. No estudo "II" o processo reverso traz vantagens econômicas com a redução da compra de embalagens e vantagens ambientais no reuso e reciclagem, pois por meio dessa ação reduziu-se o impacto ambiental. Já no estudo "III" denota-se, que o processo reverso causa redução de custo na cadeia produtiva, ganho de know-how sobre o sistema logístico completo e redução dos impactos ambientais.

De acordo com Cesar et al. (2004) mesmo com tantos benefícios a favor da reciclagem do vidro, não é isto que acontece na prática. Um material, que possui até maior potencial de reciclagem que as garrafas PET, pois pode ser reciclado infinitas vezes, não recebe a mesma atenção dispensada ao primeiro. Em termos reais os recursos investidos são para financiar as mudanças necessárias na implementação do processo logístico reverso, como a implantação de um sistema de informação para a gestão do estoque no processo "I", a implantação de um departamento para gerencial todo o processo reverso no processo "II", e a realização de um mapeamento dos principais (macros) processos da empresa no processo "III", para entender os processos produtivos e/ou operacionais atuais e assim posteriormente definir as atividades do processo logístico reverso.

Notou-se também que o processo logístico reverso depois de implantado necessita da colaboração dos atores externos para obter êxito, uma vez que os resíduos normalmente são gerados fora da organização, após o consumo, defeitos e/ou fabricação de um novo produto pelos clientes e fornecedores. Nessa perspectiva, os clientes no processo "I", fornecedores, operadores e clientes no processo "II", e clientes e fornecedores no processo "III" colaboram. Para Oliveira Neto et al. (2011), o processo de logística reversa é integrador de intenções e ações, inclusive com a participação dos indivíduos que podem contribuir, ao se desfazerem ou reutilizarem os produtos, que apresentaram algum defeito ou que pode ser reaproveitado para outras finalidades.

É deste modo que o processo de logística reversa deve funcionar, integrado com todos os atores, inclusive com os externos. Nesse contexto, se mostra factual a escolha do modelo adequado para o tipo de segmento específico. Nessa análise verificou-se que os três processos foram implementados em segmentos análogos, quais sejam: o processo "I" foi implantado numa empresa que produz e distribui seus produtos; o processo "II" em uma empresa que apenas fornece produtos acabados, e o processo "III" numa empresa que só produz seus produtos. 
No tocante ao enfoque estratégico, os produtos recicláveis do processo "I" influenciam diretamente os indicadores de desempenho da área industrial (produtividade, custos, perdas de materiais) e suas vendas, e isto faz com que uma atenção maior seja despendida a eles, principalmente na execução e controle das atividades, parte operacional da empresa. $\mathrm{O}$ aspecto estratégico no processo "II" propiciou o aumento da receita líquida da empresa. Já no processo "III" o foco estratégico possibilitou a redução do consumo de matéria-prima virgem e do custo do produto acabado, e, entre os fatores que contribuem para essa situação, destacam-se o controle das atividades e o reaproveitamento das aparas geradas no processo produtivo.

Segundo Mueller (2005), nos processos industriais é freqüente a ocorrência de sobras do processo de produção, com isso a finalidade da logística reversa é possibilitar a reutilização, bem como retirar do local aquilo que não tenha aproveitamento, deixando a área livre e desimpedida. Um subproduto do processo de fabricação em logística é refugo. Se esse material não puder ser utilizado para produzir outros produtos, deve ser removido de alguma maneira.

Isso posto, vale-se ressaltar que os três processos descritos nos estudos proporcionaram eficiência ecológica para as organizações, o processo "I", por exemplo, dar destinação adequada aos resíduos de vidro e a todos os outros tipos de resíduos gerados pela empresa, do mesmo modo acontece no processo "II" que recicla os resíduos de vidro e de outros materiais. Já o processo reverso "III" reusa $100 \%$ os resíduos de vidro gerados no próprio sistema produtivo e os recebidos de fornecedores e clientes. Comparando-se o desempenho dos processos percebe-se que todos apresentam resultados satisfatórios para a empresa e a sociedade.

\section{CONSIDERAÇÕES FINAIS}

Por todo o exposto, da comparação entre os três processos, conclui-se que os processos reversos têm um grau considerável de convergência. Eles convergem parcialmente em pontos muito importantes, como na infraestrutura instalada no processo reverso, nos tipos de atores externos envolvidos no processo logístico reverso, investimento demandado para implementar o processo e no enfoque estratégico e operacional adotado. No entanto, todos apresentaram praticamente os mesmos resultados, sobretudo, em relação à eficiência ecológica.

É irrefutável que o trabalho não buscou apontar qual processo reverso é melhor ou pior. Procurou-se apenas comparar os três processos, para se conhecer o seu grau de convergência e em que aspectos os processos reversos expostos nos estudos são semelhantes ou divergentes. De maneira geral, os processos de logística reversa comparados são muito parecidos e têm como objetivo comum a busca da destinação adequada dos resíduos de vidro gerados nos processos internos de produção e pelos seus clientes por meio de suas atividades. Por isso, as organizações mantêm parcerias com atores externos.

Observa-se que no processo reverso "III" os clientes recebem vantagens econômicas para participarem de forma proativa do fluxo reverso, são parcerias do tipo onde todos saem ganhando, os clientes com ganhos de escala recebem descontos no valor de compra do produto acabado, descontos de pequenas taxas, facilidades de pagamento e entrega do produto na porta. Enfim, percebe-se que quando a questão envolve a parte financeira, todos acabam participando do programa.

REUNIR - Revista de Administração, Contabilidade e Sustentabilidade - Vol. 2, nº 4, p.19-34, Set-Dez/2012. ISSN: $2237-3667$ 
A tendência é que, com o aumento das pressões legais, a necessidade de redução de custos e uma maior conscientização por parte dos consumidores que cada vez mais passam a valorizar organizações "ecologicamente corretas", esses processos de logística reversa sejam mais difundidos e comuns em organizações de todos os segmentos. Com isso se torna inquestionável a importância das análises comparativas entre os processos reversos.

Por fim, recomenda-se, para efeito de comparação, a aplicação da mesma metodologia desse trabalho em mais estudos e/ou processos de logística reversa de resíduos vítreos e também em outros segmentos da economia para que se possa ter uma visão mais "generalizável" dos benefícios da logística reversa no setor de vidros e em outros segmentos.

\section{REFERÊNCIAS}

ASSOCIAÇÃO BRASILEIRA DA INDÚSTRIA DO VIDRO. Índice de reciclagem de vidro no Brasil. Disponível em: $\langle$ http://www.abividro.org.br/index.php/28 $>$. Acesso em: $11 \mathrm{de}$ fev. 2012.

BALLOU, R. H. Logística Empresarial. São Paulo: Atlas, 1993. 392p.

BARRATT, M. Understanding the meaning of collaboration in the supply chain. Supply Chain Management: an International Journal, v. 9, n. 1, p. 30-42, 2004.

BRAGA JUNIOR, S. S.; COSTA, P. R.; MERLO, E. M.. Logística Reversa como alternativa de ganho para o varejo: um estudo de caso em um supermercado de médio porte. In: Anais do IX Simpósio de Administração da Produção, Logística e Operações Internacionais FGV/EAESP, 2006.

CÉSAR, A. P.; PAULA, D. A.; KROM, A.; Importância Da Reciclagem Do Vidro. In VIII Encontro Latino Americano de Iniciação Cientifica e IV Encontro Latino Americano de PósGraduação - Universidade do Vale do Paraíba, 2004. Anais do VIII Encontro Latino Americano de Iniciação Cientifica e IV Encontro Latino Americano de Pós-Graduação, 2004.

CHRISTOPHER, M. Logística e gerenciamento da cadeia de suprimentos. São Paulo, Pioneira, 2002.

DAHER, C. E.; SILVA, E. P. L. S.; FONSECA, A. P. Logística reversa: oportunidade para redução de custos através do gerenciamento da cadeia integrada de valor. Disponível em: $<$ http://www.intercostos.org/documentos/081.pdf $>$. Acesso em: $11 \mathrm{de} \mathrm{fev.} 2012$.

FERREIRA, A. S.; OLIVEIRA, D. C.; TAVARES, C. R.; SILVA, P. M. F. Logística reversa: um estudo da reciclagem caso no município de Campos dos Goytacazes-RJ. Disponível em: <http://www.convibra.com.br/upload/paper/adm/adm_1619.pdf>. Acesso em: 17 de set. 2011. 
FULlER, D. A.; ALLEN, J. Reverse Channel Systems. In: Polonsky, Michael J., MintuWimsatt, Alma T..(ed) Environmental marketing: strategies, practice, theory and research. London: The Haworth Press, 1995.

FLEURY, P. F. Supply chain management: conceitos, oportunidades e desafios de implementação. Tecnologística, n.39, fev.1999.

GIL, A. C. Métodos e técnicas de pesquisa social. 5. ed. São Paulo: Atlas, 2007.

GONÇALVES, M. E.; MARINS, F. A. S. Logística Reversa numa empresa de laminação de vidros: um estudo de caso. Disponível em: $\langle$ http://www.scielo.br/pdf/gp/v13n3/03.pdf $\rangle$. Acesso em: 17 de fev. 2012.

GUANIERI, P. et all. A logística reversa de pós-venda e pós-consumo agregando valor econômico, legal e ecológico às empresas. Congresso de Administração e Congresso Sul Brasileiro de Comércio Exterior, Paraná, 2005.

GLUGOSKI, M. Assim se faz o agronegócio. Jornal da USP on-line. Ano XXIV nº 845 de 22 a 28 de setembro de 2008. Disponível em: <http://www.usp.br/jorusp>. Acesso em: 19 fev.2012.

LAKATOS, E. M.; MARCONI, M. A. Técnicas de Pesquisa: Planejamento e execução de pesquisas, amostragens e técnicas de pesquisa e Elaboração, análise e interpretação de dados. 7.ed. São Paulo: Atlas, 2008.

LEITE, P. R. Logística Reversa - Meio Ambiente e Competitividade. São Paulo, Pearson Prentice Hall, 2003.

LEITE, P. R.; BRITO, E. Z. Logística Reversa de Produtos não consumidos: Uma descrição das práticas das empresas atuando no Brasil. 2005b. Disponível em:< http://www.ufpe.br/gestaoorg/index.php/gestao/article/view/142/124>. Acesso em: 17 de set. 2011.

LOURENÇO, J. C. Logística agroindustrial: desafios para o Brasil na primeira década do século XXI. Bananeiras: UFPB, 2009.

MARÇAL, L. L.; SILVA, A. C. A. Análise da gestão de logística reversa de vasilhames de vidro em uma fábrica de refrigerantes. In: XXVIII Encontro Nacional de Engenharia de Produção.

Disponível em:< http://www.abepro.org.br/biblioteca/enegep2008_TN_STO_069_492_11754.pdf $>$. Acesso em: 17 de fev. 2012.

MIRANDA, L. C.; WANDERLEY, C. A.; MEIRA, J. M. ABM versus GECON: uma Análise Comparativa. Disponível em: $<$ http://www.scielo.br/scielo.php?pid=S141565552003000200006\&script=sci_arttext>. Acesso em: 17 de fev. 2012. 
MUELLER, C. F. (2005) Logística Reversa Meio-ambiente e Produtividade. Disponível em:< http://www.gelog.ufsc.br/site/>. Acesso em: 17 de fev. 2012.

NOVAES, A. G. Logística e gerenciamento da cadeia de distribuição: estratégia, operação e avaliação. 3. ed. Rio de Janeiro: Campus, 2001. 410p.

- Logística e gerenciamento da cadeia de distribuição: estratégia, operação e avaliação. Rio de Janeiro: Campus, 2003.

. Logística e gerenciamento da cadeia de distribuição. São Paulo: Elsevier, 2007. OLIVEIRA NETO, G. C.; SOUZA, M. T. S.; SILVA, L. A.; SILVA, D.. Gestão de resíduos sólidos: um estudo sobre as vantagens ambientais e econômicas da logística reversa em uma empresa de fabricação de vidros. Disponível em: $\langle$ http://www.ead.fea.usp.br/semead/14semead/resultado/trabalhosPDF/248.pdf $>$. Acesso em: 17 de fev. 2012.

POZO, H. Administração de Recursos Materiais e Patrimoniais: uma abordagem logística. São Paulo: Atlas, 2002.

RAUEN, F. J. Elementos de iniciação à pesquisa. Rio do Sul, SC: Nova Era, 1999.

RESENDE, E. L. Canal de Distribuição Reverso na Reciclagem de Pneus: Estudo de Caso. Dissertação (Mestrado) - Pontifícia Universidade Católica do Rio de Janeiro. Rio de Janeiro, 2004.

SANTOS, L. A. A.; BOTINHA, R. A.; LEAL, E. A. A Contribuição da Logística Reversa de Pneumáticos para a Sustentabilidade Ambiental. Disponível em:〈www.convibra.com.br $>$. Acesso em: 17 de set. 2011.

SANTOS, L. M.; FERREIRA, M. A. M.; ABRANTES, L. A.; SILVEIRA, S. F. R. Investigação da oferta de crédito para micro e pequenas empresas no estado de Minas Gerais: uma abordagem por grupos estratégicos. Disponível:< http://200.169.97.104/seer/index.php/RBGN/article/view/244/492>. Acesso em: 17 de fev. 2012.

SOUZA, J. C. Reciclagem e sustentabilidade: a importância da logística. In: SPOLM Simpósio de Pesquisa Operacional e Logística da Marinha. Rio de Janeiro - Brasil, 2008.

VERGARA, S. C. Projetos e relatórios de pesquisa em Administração. 7. ed. São Paulo: Atlas, 2007.

VILLA, P. A "Bahia" de todos os Santos: a plataforma logística do eixo leste-oeste. In: Bahia - Análise \& Dados, Salvador: SEI, v. 13, n. 2, p. 203-217, 2003. 